
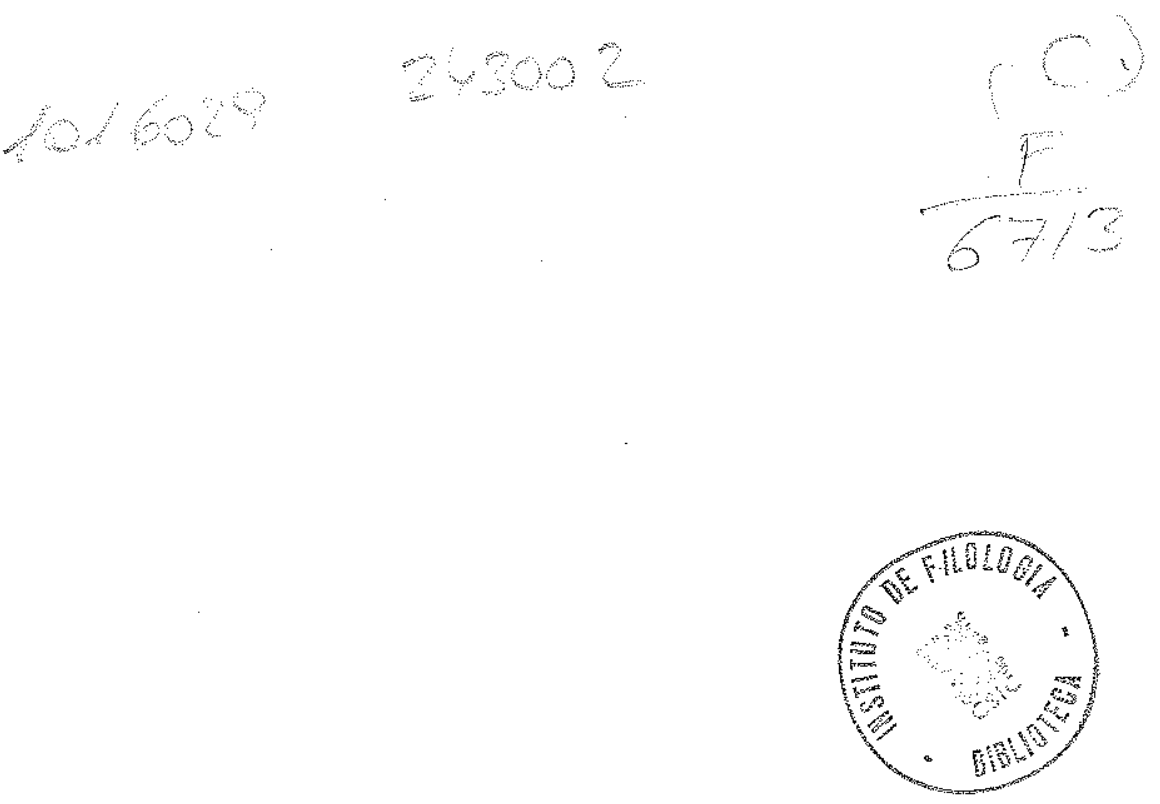

\title{
PROBLEMAS TEÓRICOS DE LA FOCALIZACIÓN NARRATIVA (PARA UNA TEORÍA "GENERAL" DE LA FOCALIZACIÓN)
}

\author{
José Luis García Barrientos
}

\section{Orientación y alcance}

El título que encabeza esta reflexión requiere, ante todo, una serie de precisiones sobre la orientación y el alcance de ésta: $l^{a}$ ) Que trataremos únicamente "algunos" de los perfiles problemáticos que presenta la cuestión, seleccionados en función de la perspectiva adoptada, que declararé enseguida. $2 .{ }^{a}$ ) Que su finalidad es la de servir de punto de partida a una discusión de los problemas que se plantean. No se adelantarán, por tanto, conclusiones resolutivas, sino meras propuestas debatibles. ${ }^{2}{ }^{a}$ ) Que con el calificativo "teóricos" quiero significar, también, que los problemas serán examinados limitándonos a su dimensión conceptual, sin apoyo en el análisis de obras concretas, que solamente serán aludidas (y raramente) en cuanto ejemplos. 4. ${ }^{a}$ ) Que entenderemos "focalización" en la acepción más estricta posible del concepto. 5.') Que el término "narrativa", por el contrario, se utiliza en su más amplia extensión conceptual, afirmación que no nos exime de alguna aclaración.

En efecto, es posible distinguir una concepción del relato o de la narratividad limitada a las narraciones literarias (verbales) de otra, más amplia, en que tienen cabida formas de representar "historias" muy diversas, como el cine, las artes plásticas, la propia historia, el cómic, etc., incluso el teatro, es decir, el otro "modo" (frente al narrativo) de representación, en términos aristotélicos. Mathieu-Colas ha estudiado la cuestión en su artículo "Fronteras de la narratología" (1986), en el que distingue dos extensiones u orientaciones de la misma, una "restringida" y otra "general (y comparada)" (p. 103), que ejemplifica en las definiciones de "relato" que sirven de base, respectivamente, a las teorías de Genette y Ricoeur. Este último (1983: 62) escribe: 


\section{JOSÉ LUIS GARCÍA BARRIENTOS}

Nosotros no caracterizamos el relato por el "modo", es decir, la actitud del autor, sino por el "objeto", ya que llamamos relato con exactitud a lo que Aristóteles llama mythos, es decir la composición de los hechos.

Para Genette (1983: 12-13), en cambio,

La única especificidad de lo narrativo reside en su modo, y no en su contenido, que puede acomodarse lo mismo a una "representación" dramática, gráfica o de otro tipo.

Si en mi libro Drama y tiempo (1991) me incliné decididamente por el partido de Genette, asumo, en cambio, ahora la perspectiva de Ricoeur para estudiar la focalización en relación con el mythos entendido como mise en intrigue. No se vea en ello veleidad o inconsecuencia, pues el cambio de presupuesto viene impuesto por el diferente objeto y propósito al que ahora atendemos.

Es, pues, en el marco de una narratología "general" en el que situamos la discusión en torno al concepto de focalización; pero tomando como punto de partida la teoría estrictamente narrativa y como puntos de referencia o de confrontación dos ámbitos en particular, los de las representaciones cinematográfica y teatral. Estoy convencido de que esta ampliación del punto de vista permitirá esclarecer no pocos puntos oscuros o problemáticos que presenta todavía la teoría de la focalización que se centra exclusivamente en las narraciones literarias (escritas). Basta evocar el círculo, probablemente vicioso, que supone la interpenetración de las categorías de "modo" y "voz".

En varios lugares del libro antes citado he tratado de justificar la relación entre literatura narrativa, cine y teatro, que no puedo ahora, so pena de no entrar nunca en materia, más que exponer como si de un axioma se tratara: cine y teatro se oponen a narrativa literaria en cuanto espectáculos o representaciones no exclusiva ni primordial ni necesariamente verbales, sino primordial y necesariamente "visuales". La oposición modal mímesis/diégesis permite oponer el teatro (modo dramático) a las dos manifestaciones del modo narrativo, literatura y cine. El rasgo distintivo más general de la oposición modal radica, a mi entender, en el carácter "mediato" o "inmediato" de las respectivas representaciones: tanto el cine como la literatura representan un "mundo" a través de una instancia mediadora, el "ojo" de la cámara y la "voz" del narrador, el teatro lo despliega ante los ojos del espectador sin mediación alguna. Resultaría así, destacando los rasgos pertinentes, el sistema:

\begin{tabular}{|c|c|c|}
\cline { 2 - 3 } "RELATO" & Mediato & Inmediato \\
\hline Visual & CINE & TEATRO \\
\hline Verbal & NARRACIÓN LITERARIA & \\
\hline
\end{tabular}

Salta a la vista, si esto es así, el interés que para una teoría de la focalización tiene atender precisamente a estos tres tipos de "relato" (la casilla vacía debería ocuparla seguramente el texto dramático).

Una vez establecidas las reglas, podemos adentrarnos en los problemas, pero no sin antes traer brevemente a la memoria lo que servirá de punto de referencia a todas las consideraciones, es decir, la teoría de la focalización de Gérard Genette. 


\section{PROBLEMAS TEÓRICOS DE LA FOCALIZACIÓN NARRATIVA}

\section{Teoría de la focalización de Genette}

Es el de "focalización" un concepto que la narratología debe a Genette. Y no tanto porque se tratara de una categoría que hubiera pasado desapercibida a los análisis o teorizaciones anteriores, sino porque hasta la aparición del "Discurso del relato" no había sido convenientemente "aislada" de otras que, aunque estrechamente relacionadas, resulta ventajoso no confundir con ella. Denominaciones como "punto de vista", "visión" o "perspectiva" cubrían el tratamiento "pregenettiano" del concepto. En la preferencia de Genette por el término (más abstracto) de "focalización", que había sido puesto en circulación por autores como Brooks y Warren, que hablan de "foco de narración" (focus of narration), puede advertirse ya la orientación que apunta a desligar el concepto de relaciones, necesariamente metafóricas, con lo visual.

Pero lo que resulta esencial para el desarrollo posterior de la narratología es la separación (la distinción ya había sido notada por Henry James) entre fenómenos o categorías pertenecientes a la "voz" y al "modo" narrativos. Así, que un relato se haga en primera o tercera persona, que el narrador sea uno de los personajes o se sitúe fuera de la historia que cuenta, son cuestiones que afectan a la voz y no al modo; mientras que el que determinada acción sea percibida por tal personaje o sujeto, independientemente de quien la cuente, es cuestión relacionada con el modo y no con la voz. La distinción se plantea, incurriendo en personalización no exenta de problemas, como veremos, en términos de "¿Quién habla?" (voz) y “QQuién percibe?” (modo). Con mayor precisión, las categorías que responden a cada una de las preguntas serían, respectivamente, la de "narrador" y la de "focalización", aunque más congruente sería decir la de "focalizador" (concepto éste que Genette se resiste a admitir).

Una vez establecido el deslinde, la crítica de Genette a las teorías anteriores, que lo ignoran, resulta clarificadora. En sus palabras (1972: 203):

Mi crítica de las clasificaciones anteriores (Brooks-Warren, Stanzel, Friedman, Booth, Romberg) se refiere evidentemente a la confusión que operaban entre modo y voz, bien (Friedman, Booth) al bautizar como 'narrador' a un personaje focal que no abre la boca, bien al inventariar situaciones narrativas complejas (modo + voz) bajo la rúbrica de 'punto de vista': es evidentemente el caso de Brooks-Warren, Friedman y Booth, pero mucho menos, a decir verdad, el de Stanzel y Romberg, a los que se puede sólo reprochar el alinear como equivalentes diferencias de punto de vista y de enunciación narrativa.

Tomando como criterio el grado de (creciente) restricción de la información narrativa, distingue Genette tres tipos:

1. Focalización cero o no focalización, que corresponde al relato en que el narrador "dice más de lo que sabe ningún personaje", característica de la novela clásica (decimonónica) definida por la "omnisciencia" del narrador, y que puede relacionarse con la fórmula de Todorov "Narrador>Personaje", con la "visión por detrás" de Pouillon y con el "tipo auctorial" de Lintvelt.

2. Focalización interna, en que el narrador "no dice más de lo que sabe un personaje", de lo que tal personaje puede percibir desde su punto de vista, y cabe relacionar con la fórmula "Narrador=Personaje" de Todorov, la "visión con" de Pouillon, el relato de "punto de vista" de Lubbock, el "campo restringido" de Blin o el "tipo actorial" de Lintvelt. Ésta puede ser, a su vez: fija, si se mantiene el mismo personaje como sujeto o conciencia focal a lo largo del relato; variable, si el foco pasa de uno a otro personaje, siempre que cada uno foca- 


\section{JOSÉ LUIS GARCÍA BARRIENTOS}

lice distintos contenidos diegéticos; y múlitiple, si distintos personajes se van alternando en la focalización "de una misma historia".

3. Focalización exierna, en que el narrador "dice menos de lo que sabe el personaje", y supone, por tanto, la restricción mayor de la información narrativa. Corresponde al relato objetivo o "behaviorista" en que el personaje o el objeto se presenta desde el exterior y no puede hablarse propiamente de "sujeto" de la percepción (pues se trataría entonces ya de focalización interna). Cabe relacionar este tipo con la fómmula de Todorov "Narrador $<$ Personaje", con la "visión desde fuera" de Pouillon y con el "tipo neutro" de Lintvelt.

El propio Genette advierte que la frontera entre los tres tipos no es tan neta como pudiera parecer: una focalización externa en relación a un personaje puede ser interna respecto a otro; a veces resulta difícil distinguir la focalización variable de la no focalización, que podría entenderse como una multifocalización ad libitum; en cuanto a la focalización interna, raramente se encontrará aplicada rigurosamente, lo que exigiría que el personaje focal no fuera nunca đescrito ni designado desde fuera: considera Genette que sólo alcanza su realización plena en el "monólogo interior" y señala como criterio mínimo el que Barthes (1966) considera distintivo del "modo personal": la posibilidad de reescribir el fragmento en primera persona sin más alteración que el cambio de pronombres (cfr. Cohn, 1985, y Cohn-Genette, 1985).

Dos precisiones más para cerrar este recordatorio de lo que constituye el punto de referencia de cuanto sigue, es decir, el modelo teórico de Genette. La primera se refiere a las posibilidades combinatorias de distintos tipos de focalización en un mismo relato. La ley que rige las variaciones de focalización es la de que "el que puede lo más puede también lo menos", pero no a la inversa. Brevemente, un relato no focalizado puede, en determinados momentos, adoptar la focalización interna o externa. No es posible (o por lo menos coherente), en cambio, que en un relato focalizado tenga cabida un segmento en focalización cero, de narrador "omnisciente", o que otro en focalización externa acoja fragmentos focalizados por un personaje.

Muy relacionadas con las variaciones (y muy difícil, por eso, de separarlas, en el análisis concreto, de ellas y de otros fenómenos: el suspense, las anacronías, la distancia entre personaje-narrador y personaje-actor, etc.) se presentan las alteraciones de focalización, que suponen "infracciones aisladas, cuando la coherencia de conjunto se mantiene lo bastante fuerte como para que la noción de modo dominante siga siendo pertinente" (1972: 211) y son de dos tipos: paralepsis, por la que se ofrece más información de la que cabe esperar del tipo de focalización que rige el contexto; y paralipsis, mediante la que se oculta, por el contrario, información que el tipo de focalización permite ofrecer.

\section{Focalización y visión}

Las preguntas “¿quién ve?” y “quién percibe?”, que alternan, o mejor, se suceden en Ios "Discursos" de Genette, no son evidentemente sinónimas. La segunda incluye la primera y la excede. También cabe decir que la aventaja (además de en extensión) en "propiedad" siempre que el concepto se aplique a la narración literaria, que no es susceptible, en sentido literal, no figurado, de "visión" alguna. Pero si se trata (como en nuestro caso) de perfilar el concepto en el ámbito, más amplio, del relato o las representaciones, verbales o no, y particularmente referido a aquél o aquéllas de carácter primordialmente visual, como el cine y el teatro, parece conveniente, si no imprescindible, distinguir el modo de visión, lo que François Jost denomina ocularización (1983: 196), de los restantes modos de percepción. La 


\section{PROBLEMAS TEÓRICOS DE LA FOCALIZACIÓN NARRATIVA}

indistinción, que quizás favorezca la operatividad del concepto en su aplicación a la literatura narrativa, sin duda obstaculiza un análisis riguroso de los factores constructivos de las representaciones cinematográfica (lo que parece obvio) y dramática (lo que puede no advertirse con la misma claridad).

Cuando Étienne Souriau (1950) imagina una inversión del modo de presentar la escena VI del acto III de Britannicus de Racine, haciendo visible en escena a Nerón, que escucha la conversación que mantienen detrás de la cortina (invisibles, por tanto) Británico y Junie (págs. 236-237, n. 1) apunta a un efecto de "ocularización", mientras que cuando se refiere al "punto de vista" dramático como "perspectiva moral" (p. 128) o "puerta de entrada a través de la cual el espectador ve en perspectiva el interior de la situación" (p. 124) y afirma que en Casa de muñecas de Ibsen el punto de vista es predominantemente el de Nora, hasta la última escena, en que se produce un patético desplazamiento hacia el punto de vista de su marido, nos hallamos ante el concepto amplio de focalización o "modo de percepción" en general.

Pero la vía que abre la posibilidad de tomar en consideración el concepto de "ocularización" o focalización visual no necesariamente debe cerrarse tras ella. Aunque seguramente resultaría extremoso establecer una tipología según el sentido que intervenga en la percepción, no parece desde luego descartable la utilidad de distinguir una focalización estrictamente auditiva, a la que, por cierto, alude Genette en el Nuevo discurso (cfr. Nelles, 1990: 378). Aunque seguramente resultará pertinente también en el análisis de algunos relatos literarios, pienso ahora en un ejemplo teatral: El sueño de la razón de Buero Vallejo. ¿Se podría dar cuenta de su peculiar "forma de presentación" de los hechos, personajes, palabras y objetos sin poner de manifiesto que la focalización en Goya que la caracteriza se manifiesta en una doble restricción (y consiguiente "deformación") de la percepción (del protagonista y del público "obligado" a identificarse con él): de carácter visual una, que da lugar a alucinaciones justificadas por la "locura" del personaje, y otra, quizás más interesante, o por lo menos más llamativa, de carácter auditivo, justificada por su sordera, que se traduce en la percepción de ciertos diálogos como puro silencio o a través de la imaginación acústica deformante del personaje-público? Es, pues, un juego de ocularización y auricularización (Jost, 1983: 210) el que define, desde el punto de vista sensorial, la focalización del protagonista, que constituye seguramente el principio constructivo básico del drama.

La primera propuesta es, pues, considerar pertinente para una teoría "general" de la focalización, entendida como restricción perceptiva, la distinción entre focalización no sensorial (que trataremos más adelante) y sensorial, y en ésta, a su vez, entre focalización visual u "ocularización" y focalización auditiva o "auricularización".

\section{Focalización interior y exterior}

Examinaremos ahora la utilidad de introducir un nuevo criterio distintivo en el concepto de focalización. Bal, Vitoux y Lintvelt, entre otros, coinciden en referir tal distinción al "objeto" focalizado. En términos de Bal, se trata de oponer lo visible, o mejor, lo "perceptible" (entiéndase sensorialmente: por alguno de los cinco sentidos) y lo invisible o "imperceptible". Vitoux, siguiendo el mismo criterio pero rechazando las denominaciones de Bal (pues considera, con razón, que las realidades no sensoriales no dejan de ser perceptibles, aunque lo sean de otra forma o por otro conducto), distingue una "focalización objeto externa" de otra "interna". Lintvelt, por su parte, remite la cuestión al concepto de "profundidad de la perspectiva narrativa" y distingue la "perspectiva externa" de la "interna", cada una de las cuales puede ser, a su vez, "Timitada" o "ilimitada". Se trata, en definitiva, de distinguir la naturaleza objetiva o subjetiva de lo representado, su pertenencia al "mundo" (ficti-

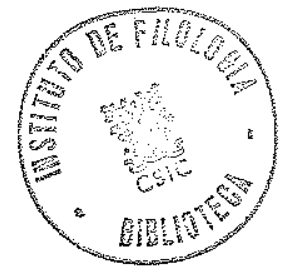




\section{JOSÉ LUIS GARCÍA BARRIENTOS}

cio) o al contenido de conciencia -sueños, imaginaciones, pensamientos, deseos, temores, etc.- de un personaje o sujeto (también ficticio). La pertinencia de la distinción es, a mi juicio, clara. Precisamente uno de los síntomas de la omnisciencia ha sido considerado siempre esa capacidad de penetración en la intimidad de los personajes, incluso más allá de lo que ellos mismos son capaces de percibir en su interior.

Recurrir al cine permitirá "ver" (en efecto) esta cuestión con la máxima nitidez y referida a su apariencia más inmediata: la visión. Tanto la "cámara objetiva" (posición de un ojo ajeno a la historia filmada) como la "subjetiva" (situada en el ojo de un personaje de la película) registran imágenes que pertenecen al mundo exterior, visto desde fuera, en el primer caso, o desde la mirada de un personaje, en el segundo. Por el contrario, cuando se "pone en imágenes" una alucinación o una pesadilla, la cámara se asoma al mundo interior de un sujeto (¿necesariamente de un personaje?). Y puede, me parece, hacerlo desde los ojos del que sueña o sufre la alucinación (cámara subjetiva) o desde fuera (cámara objetiva). En el segundo caso, quien sueña podrá figurar en las imágenes del sueño, o quien alucina, en las de la alucinación. La diferencia entre el carácter subjetivo o no del contenido de las imágenes y la posición subjetiva o no del punto de mira, salta así (nunca mejor dicho) a la vista. En cualquier caso, es un hecho que el cine ha ido codificando una serie de marcas formales (zoom sobre el rostro del personaje, desenfoque, ralentización de las imágenes, etc.) que permiten diferenciar inequívocamente a cualquier espectador las imágenes interiores de las externas o "reales".

La distinción, funđamental también para el análisis de las imágenes en las artes plásticas (cfr. Van Alphen, 1990: 499-500, nota 10), es igualmente operativa en las representaciones dramáticas o teatrales: piénsese en La muerte de un viajante de Arthur Miller, por ejemplo. Lo que varía son las marcas formales y el grado (menor) de codificación o "automatización" de las mismas: en el caso citado es el espacio escénico el encargado de señalar el carácter interiorizado o "real" de las diferentes escenas.

En lo que se refiere a la literatura narrativa, lo difícil sería seguramente encontrar ejemplos en que no se ponga de manifiesto la diferencia aludida, relatos cuyo caudal de información narrativa no se nutra, en la medida que sea, de datos externos u objetivos e internos o subjetivos. Hasta una novela casi totalmente interiorizada como Cinco horas con Mario de Miguel Delibes no deja de presentar un marco narrativo "objetivo".

El conflicto terminológico en que entran las denominaciones "externa" e "interna" para referirse a esta diferencia de focalización con las de la tipología de Genette puede soslayarse provisionalmente, y sólo para entendernos, llamando focalización interior a la que supone percepción "de lo interno" de un personaje u objeto, y focalización exterior a la que implica percepción "de lo externo" de tal objeto o personaje. (Por cierto, ¿no será la "interior" la única forma posible de focalización visual "interna" en el teatro?) Quede, con la pregunta, nuestra defensa de la pertinencia de distinguir, referidas al objeto de la percepción, una focalización "interior" de otra "exterior" como segunda provocación a la discusión teórica.

\section{Punto focalizante y objeto focalizado}

Implícita en el planteamiento del problema anterior se hallaba la distinción entre sujeto focalizador y objeto focalizado, que hacen suya, además de Mieke Bal, Vitoux, en términos de focalización-sujeto y focalización-objeto, y Lintvelt, bajo las denominaciones de perspectiva narrativa (de narrador, de actor, de cámara, de personaje-narrador o de personajè-actor) y profundidad de la perspectiva narrativa (interna o externa, limitada o ilimitada). Con ellos 


\section{PROBLEMAS TEÓRICOS DE LA FOCALIZACIÓN NARRATIVA}

o tras ellos no pocos narratólogos las han adoptado como categorías pertinentes para el estudio de la focalización. Así, por ejemplo, Susana Reisz de Rivarola (1985), Sandro Briosi (1986), William Edmiston (1989), Ruth Ronen (1990), etc.

Sin embargo, Genette, en el Nuevo discurso del relato, considera abusiva la conversión, por parte de Bal, de la focalización en "instancia narrativa". Cierto es que en su pregunta "¿quién percibe?" está implícito un "sujeto", expresamente aludido por él en ocasiones. De la misma forma que con el paso de "quién ve" a "quién percibe" se trataba de librar a la focalización de su relación con lo visual, para desvincularla del cariz psicológico (y librarla, por tanto, del presunto focalizador) Genette redefine el concepto como "una restricción de "campo" o una "selección de la información narrativa en relación a lo que la tradición 1lamaba la 'omnisciencia"' (1983: 49), y señala como instrumento de esa selección no un sujeto, sino un "foco situado", una especie de tapón que no deja pasar más información que la que autoriza la situación.

En focalización interna, ese foco coincide con un personaje. Parece que, por lo menos en este caso, puede hablarse con propiedad de focalizador para referirnos al denominado por el mismo Genette "sujeto' ficticio de todas las percepciones" (1983: 49). En focalización externa, el foco se sitúa en un punto del universo diegético elegido por el narrador "fuera de cualquier personaje", lo que excluye la posibilidad de que deje pasar información sobre los pensamientos (el interior) de cualquiera de ellos. La focalización cero, ¿supone la ausencia de foco, de tapón? En buena lógica, así debería ser. El asunto, en cambio, es más que problemático. Genette llega a admitir que en muchos casos este tipo coincida con (o resulte de) una focalización "variable"; pero a veces, insiste, el concepto de no-focalización lo define mejor. Se refiere al famoso "punto de vista de Dios", en el que el "foco" se sitúa en un punto tan indeterminado, tan lejano, tan potente o abarcador y penetrante que no parece posible hacerlo coincidir con el de ningún personaje o sujeto.

Ahora bien, lo que pianteamos ahora no es si la distinción focalizador/focalizado se sigue necesariamente o no (como remedio de una disimetría o una incoherencia) del aparato conceptual de Genette, sino simplemente si puede resultar útil para la descripción de la forma de presentación o de construcción de un relato, del tipo que sea. Precisamente en su defensa (ya comentada) de la no-focalización, que pondría en entredicho al menos el carácter "general" del concepto de focalizador, Genette comenta: "A diferencia del cineasta, el novelista no está obligado a poner la cámara en ningún sitio: no tiene cámara" (1983: 49). Invirtiendo los términos de la proposición, el cineasta, que sí tiene cámara, no tiene más remedio que ponerla en algún sitio (cffr. Robbe-Grillet, 1958: 129).

Afirmar la utilidad del concepto de focalizador, como categoría "general", exige ante todo desvincularla de implicación personal alguna. No parece oportuno, para ello, recurrir a denominaciones como "sujeto" de la focalización o "agentes" (Rimmon-Kenan, 1983: 138), que, siendo menos económicas, no dejan de presentar connotaciones de personalización. Si acaso, dejándome llevar por la tentación nominalista, me inclinaría a proponer, sobre el modelo del signo saussureano, los términos de punto focalizante y objeto focalizado, aunque quepa considerar que bastaría con dotar expresamente al concepto de "focalizador" de un grado de abstracción tal que admita una serie de actualizaciones, según los casos, de lo personal a lo impersonal, de lo antropomórfico a lo puramente "tópico" (de lugar).

En el cine, y limitando la focalización a la estricta visión, cabe entender por punto focalizante el lugar (y ángulo) en que se sitúa la cámara. Cuestión posterior será determinar si ese lugar corresponde o puede corresponder (pensemos en el "ángulo imposible") al ojo de un personaje. Sólo en este caso puede hablarse con propiedad de "sujeto" (y no, en general, de 


\section{JOSÉ LUIS GARCÍA BARRIENTOS}

"punto") focalizante. De todas formas, lo que resulta evidente, una vez definido así el concepto, es que no hay imagen o relato cinematográfico posible sin punto de focalización.

Este desplazamiento de la categoría de focalización desde un sujeto hasta un lugar o una posición de referencia puede advertirse, referida a la narración literaria, en la fórmula que propone Paul Ricoeur (1984: 148) para definir el "punto de vista" en forma de pregunta (no ¿quién? sino): "¿Desde dónde se percibe lo que es mostrado por el hecho de ser contado?" (nótese que el autor mantiene para la definición de la "voz" el interrogante "¿Quién habla aquí?"). En la fórmula, por otra parte, intervienen (y son distinguibles, por tanto) tres elementos: un punto focalizante ("desde dónde"), un objeto focalizado ("lo que es mostrạo") y una relación de dependencia (¿podría decirse de subordinación?) tanto de lo focalizado, directamente, como, indirectamente, del punto focalizante respecto a la voz ("por el hecho de ser contado"). Volveremos sobre esta relación más adelante. Lo que interesa resaltar ahora es que, así como Marie-Laure Ryan (1981: 519) afirma el carácter lógicamente necesario del narrador en todas las ficciones, se puede predicar (y con más propiedad), para cualquier forma de representación, la necesidad de un "focalizador", entendido como el lugar (físico o no, subjetivo o no) desde el que se percibe lo que es mostrado, visual o verbalmente, es decir, de lo que hemos dado en llamar punto focalizante.

En cuanto al objeto "focalizado", al que nos referimos en el problema anterior como soporte de la distinción (planteada en términos estrictamente psicológicos) entre focalización interior y exterior, deben hacerse ahora dos precisiones: la primera, señalar la relación de implicación recíproca que contrae con el punto focalizante: cualquier objeto focalizado supone lógicamente (y se puede definir en relación con) un punto focalizante, y viceversa. La segunda, plantear la posibilidad, paralela, de "de-psicologizar" el objeto de la focalización. Y, en efecto, creo que la percepción de lo interior puede referirse tanto al interior de una mente como al interior de un cuerpo o al interior de un objeto. Y que pasar de describir el rostro (exterior) de un personaje a describir su pensamiento (interior) implica un cambio de perspectiva, un desplazamiento del "punto de vista" o del "foco" de percepción, si no idéntico, muy similar al que exige la descripción de una naranja por fuera y por dentro (sin abrirla, naturalmente). Me viene a la mente la serie televisiva de dibujos animados sobre "El cuerpo humano": ¿no se trataría de un ejemplo de focalización "interior" de carácter no psicológico?

En síntesis, una vez admitida la utilidad de distinguir el punto focalizante del objeto focalizado, podría expresarse en la oposición personal/impersonal (cfr. Doležel, 1980, Ryan, 1981, y Ronen, 1990) la posibilidad de que tanto el punto como el objeto de focaližación puedan coincidir o no con un personaje o sujeto. Lo que antes definimos como focalización "interior" o "exterior" puede ahora referirse (por su recíproca implicación) a la "penetración" (o no) tanto del punto focalizante como en el objeto focalizado. Nada, por último, parece oponerse a que cada uno de los tipos, personal e impersonal, admita las dos posibilidades, exterior e interior.

\section{Tipología}

Admitida, aunque sea provisionalmente, la distinción entre punto focalizante y objeto focalizado y considerando que este último puede ser percibido (desde el punto focalizante) y, por tanto, mostrado (por la instancia narrativa) en su exterior o en su interior, podemos volver a examinar la tipología de Genette y sus críticas. Bal, Lintvelt y Vitoux coinciden en señalar que la focalización externa no se define, como los otros dos tipos, en relación al focalizador (de percepción ilimitada o limitado a la percepción de un personaje), sino al objeto focalizado, que es en este caso percibido (y mostrado) en su "pura objetividad". Para Gérard 


\section{PROBLEMAS TEÓRICOS DE LA FOCALIZACIÓN NARRATIVA}

Cordesse (1988: 488) la discontinuidad lógica de la clasificación no sería más que aparente. En sus palabras:

Es porque en focalización externa, la menos poderosa, el focalizador, ese testigo anónimo y virtual, tiene muy poco poder por lo que parece desaparecer en beneficio de lo focalizado, pero no se trata, después de todo, más que de un efecto de realidad.

Desde nuestro punto de vista, no se puede negar un focalizador a la focalización externa, so pena de tener que negárselo también a la focalización cero. Pues ello supondría exigirle el estatuto de personaje de la historia. Tal como hemos propuesto concebirlo antes, el concepto de focalizador (como punto focalizante) es lógicamente inseparable del de objeto focalizado: uno implica el otro y, por tanto, cualquiera puede definirse en relación con el otro. Son, pues, si se quiere, conceptos redundantes, o mejor, las dos caras del mismo concepto, enfocado desde dos puntos de vista distintos. Y aunque me sigue pareciendo útil diferenciarlas, la coherencia de la clasificación de Genette resulta, desde este fanco, inatacable, a mi juicio.

Consideremos un momento la tipología que, siguiendo en lo esencial a Bal, propone Vitoux (1982) y que se basa en la distinción entre "Focalización sujeto" (Fs) y "Focalización objeto" (Fo). Esta última puede ser "externa" (de lo perceptible) o "interna" (de lo imperceptible por los sentidos). Y la focalización sujeto (Fs), "delegada" o "no delegada" por el narrador. Al combinar las dos dicotomías resulta que a la $F s d$ corresponde como única posibilidad la Fo ext, mientras que la $F_{S}$ nd admite las dos: $F_{O}$ ext y $F_{O}$ int. Aparentemente, se obtienen también tres parejas, que se podrían intentar acoplar con los tipos de Genette:

Fs d - Fo ext $\sim$ Focalización interna

Fs nd - Fo ext $\sim$ Focalización externa

Fs nd - Fo int $\sim$ Focalización cero

Aunque seguramente la correspondiente a la focalización cero sería, más bien, no la pareja, sino el trío:

Fs nd - Fo int - Fo ext

Alfonso Sánchez-Rey (1991) propone dos criterios que, aunque en el fondo coinciden con los de Vitoux, parecen encajar mejor con los tipos genettianos: de una parte, la restricción o no de la información; de otra, la oposición entre relato "modalizado", con disociación de los conceptos de narrador y focalizador, y "no modalizado", con fusión de las dos categorías. Así resultan los tipos:

\begin{tabular}{|l|c|l|}
\hline Sin restricción & F. cero & \\
\hline Con restricción & F. externa & F. interna \\
\hline \multirow{2}{*}{} & No modalizado & Modalizado \\
\cline { 2 - 3 }
\end{tabular}

La cuarta posibilidad combinatoria parece, en principio, contradictoria. Como tal, la descartan no sólo Genette, Vitoux y Sánchez Rey, sino también Bal (1985: 115) y Óscar Tacca (1973: 72 y 85), entre otros. Sin embargo, en un artículo estimulante cuanto discutible, Pilar Rubio Montaner (1990: 61-64) defiende la cuadratura del triángulo al "reivindicar la focalización interna ommisciente" (p. 65), no como una "infracción", sino como un tipo más, que encuentra plenamente realizado en Bomarzo de Mújica Laínez. Dando por supuesto 


\section{JOSÉ LUIS GARCÍA BARRIENTOS}

que no se trata de una confusión entre modo y voz, su argumento, que se basa en el rechazo del principio de analogía (Pouillon, 1946: 36) entre la visión o percepción narrativa (ficticia) -"donde todo debería ser posible" (p. 63) - y la real, llevaría, más que a admitir esta cuarta posibilidad, a negar, en último término, no sólo la tipología, sino la teoría toda. Lo que sí pone de manifiesto es quizás la conveniencia de hacer explícita la limitación de la teoría que consideramos al ámbito de los relatos o las ficciones que se atienen al principio de "verosimilitud", tal como lo entendía Aristóteles (cfr. Genette, 1990, esp. 761-763), o bien a los que se encuadran en la segunda categoría de la división tripartita de san Isidoro (Etimologías, Lib. I, cap. 44):

La historia es de cosas verdaderas que han ocurrido; el argumento es de las cosas que, aunque no han ocurrido, son posibles, y las fábulas son aquellas cosas que ni han ocurrido ni pueden ocurrir porque son contra la naturaleza.

Curiosamente, es quizás más problemática la frontera entre las dos primeras categorías (cfr. Villanueva, 1991) que el límite entre éstas y la tercera.

Los dos modelos considerados ponen de manifiesto las mismas afinidades: entre focalización cero y externa en cuanto ambas suponen una "focalización sujeto no delegada" o dan lugar a un relato "no modalizado"; entre focalización externa e interna en cuanto ambas implican restricción perceptiva o se limitan a una "focalización objeto externa". Ninguno de los dos, en cambio, da cuenta (a no ser implícitamente) del carácter "gradual" de la restricción informativa que pone de manifiesto la tipología de Genette, que, como afirma Briosi (1986: 517), "es, por tanto homogénea en cuanto a la 'ciencia del narrador' que disminuye" y, en su opinión, "defendible contra ese tipo de críticas, justamente, quizás, gracias a esa falta de homogeneidad, en la que se podría ver también un signo (con todos sus peligros) de la autoironía (o de la inteligencia) que Genette explicita al final de su libro: "La crítica dice siempre demasiado. Lo mejor sería quizás [...] no "acabar" nunca, es decir, en cierto sentido, no comenzar nunca" (p. 273).

No resulta difícil establecer la correspondencia entre el relato "no modalizado" y el focalizador-lugar o no-personaje que denominamos antes "impersonal", de una parte, y de otra, entre el relato "modalizado" y el focalizador-personaje o "personal". Ello permite explicar el recurso al "narrador", no como causa, sino como consecuencia del tipo de focalización. En efecto, cuando ésta es ya personal, la "persona" que habla, el narrador, viene a sumarse a ella y resultan por eso distinguibles (hay dos personas: una percibe, otra dice lo que ésa percibe): la focalización personal es una instancia "opaca"; en la impersonal, instancia transparente, la ausencia misma de "persona" (no de punto) que perciba hace que parezca que la única persona ahora, la que habla, es también la que percibe, el narrador ocupa así el lugar, vacío, de un focalizador-personaje. Se trata, en definitiva, de darle la vueita al concepto de "delegación" de Vitoux, entendiendo que es el focalizador impersonal el que "delega" su representación en el narrador.

Todavía, si tenemos en cuenta que es precisamente el criterio de la restricción informativa el que define para Genette el concepto mismo de focalización, habrá que concluir que resulta superfluo como criterio clasificatorio. Lo coherente será, pues, hablar de dos tipos de focalización, interna (o personal) y externa (o impersonal), frente a la ausencia misma de focalización o no restricción. La dificultad estriba, claro está, en admitir la posibilidad de un relato que ofrezca verdaderamente una información no resiringida; posibilidad que hay que descartar, creo, sin necesidad de plantear la "cualidad" sino sólo atendiendo a la cantidad de información. No hay focalizador (punto o sujeto) capaz de saber o percibir literalmente todo lo que forma parte de un suceso, de un personaje, de un objeto. El llamado "punto de vista de 


\section{PROBLEMAS TEÓRICOS DE LA FOCALIZACIÓN NARRATIVA}

Dios" habría que entenderlo más como una hipérbole que como una metáfora. Todo relato (como toda construcción y toda percepción humana) implica selección informativa, y por tanto restricción, es decir, focalización.

Lo que ocurre es que ésta puede autosometerse (o ser sometida, en definitiva por el "autor" del relato) a unas reglas estrictas que definan con rigor un "punto de vista" (de percepción), o no. En el primer caso cabría hablar -sólo para entendernos- de focalización explícita; en el segundo, de focalizacion implícita. Aquélla descubre sus reglas restrictivas; ésta las oculta, de forma que sólo podrán establecerse (partiendo de que serán menos "estrictas") a través del análisis de la "composición" del relato. Podría bien, por eso, denominarse también "implicada" (por el mundo representado), mientras que la explícita "implica" más bien una forma de representar ese mundo. Cabe plantear como motivo de reflexión el modelo:

$$
\begin{array}{l|l|l}
\text { Focalización } & \begin{array}{l}
\text { Implícita } \\
\text { Explícita }
\end{array} & \text { Interna (Personal) } \\
& \text { Externa (Impersonal) }
\end{array}
$$

Nótese que una de las formas que puede adoptar la focalización implícita (y bajo la que debemos descubrirla) es la conjunción y alternancia de distintas focalizaciones explícitas (internas o externas). Así, por ejemplo, la narración en focalización externa de dos episodios que sean simultáneos en la historia "implica", para el conjunto de los dos, una focalización más poderosa (omnisciencia) de carácter "implícito".

\section{Focalización y narrador}

Aunque ha sido y sigue siendo nuestro propósito el empeñarnos en reconocer la frontera entre modo y voz, es decir, la distinción entre narración y focalización, lo cierto es que en el relato literario (pero quizá no en otros) resulta muy difícil de sostener. Parece, en efecto, insuficiente la delimitación genettiana de ambos dominios (Van Rees, 1985: 448450), pues la definición del modo presupone una instancia narrativa, implica en definitiva un punto de vista del narrador (ibíd.: 449). Basta recordar las definiciones de Genette, que comienzan: "El narrador dice..." (más, lo mismo o menos de lo que sabe el personaje). Ricoeur (1984: 148) señala que las nociones de punto de vista y de voz son "tan solidarias que resultan indiscernibles" y que no faltan, en efecto, los análisis que pasan sin transición de una a otra, como los de Bajtin, Lotman o Uspensky. Cabría añadir que tanto en la fase pre- como post-genettiana de la teoría. El trabajo de Reisz de Rivarola (1985) que citamos antes es una buena muestra (postgenettiana) de consideración conjunta de la voz, la focalización y la distancia.

Sin salir del relato "literario", valdrá la pena hacer un esfuerzo todavía por mantener la delimitación o, al menos, "la relativa independencia del modo y de la voz", que ve Genette (Cohn y Genette, 1985: 109) confirmada en el estudio de Dorrit Cohn (1985) sobre El castillo de Kafka. Y ello para plantear una cuestión que puede resultar, a la postre, esclarecedora: la de la relación "jerárquica" entre narración y focalización.

Rubio Montaner (1990) defiende la "primacía de la focalización en la instancia narrativa". Parte de la tesis de Bal (1985: 126) de que "juntos, el narrador y la focalización, determinan lo que se ha dado en llamar narración". Y entiende que "la voz traduce sólo los datos que le proporciona la focalización e incluso menos" (p. 65). Esta última posibilidad se pone 


\section{JOSÉ LUIS GARCÍA BARRIENTOS}

de manifiesto, según ella, en el monólogo interior de "flujo de conciencia" en las ocasiones en que existen elementos focalizados que no se verbalizan (cabe preguntarse cómo se descubren esos elementos si no es a través de la voz). Y concluye: "esto demuestra que el plano de la voz es un derivado del plano de la focalización" (p. 65) y esta prioridad (que no independencia) puede ser la causa de que las tipologías anteriores a Genette se centraran en el "punto de vista", omitiendo o ignorando la voz.

Por el contrario, Dorrit Cohn (Cohn y Genette, 1985: 105) señala que la elección de persona (gramatical) es la primera que hace el autor en el orden del discurso y es más importante que otras, como la focalización, que puede variar de una frase a otra, mientras que la persona está fijada (en el relato clásico) de una vez por todas, de principio a fin. Los esquemas de Doležel (1967: 552), Cordesse (1988: 496) y Husson (1991: 310), que se prestan, desde luego, a la discusión sobre otros muchos puntos, ponen de manifiesto la prioridad (determinante) que conceden los autores a la voz respecto a la focalización. El concepto de "prefocalización" de Genette se puede interpretar en el mismo sentido. Reisz de Rivarola (1985) apunta que lo narrado implica un objeto focalizado (pero no al revés) y que un cambio de voz implica un cambio de focalización (pero no al revés).

La cuestión, que algún parecido presenta con la de "gué fue primero, el huevo o la gallina", cobra la apariencia, como ya sugerimos, de un auténtico círculo vicioso, del que se puede escapar de varias maneras: anulando la frontera entre narrador y focalizador, en beneficio quizás del "autor", excluido del análisis narratológico, en la dirección apuntada por Briosi (1986); haciendo que el focalizador desplace de su lugar al "autor implícito", como propone Bal (1983: 238 y 250); o prescindiendo del focalizador como nueva categoría redundante e innecesaria, como sugiere Nelles (1990: 373). Ninguna de ellas nos conviene en el intento de mantener al narrador y a la focalización como conceptos operativos. Y sí plantear la cuestión de otro modo, salir del círculo, como suele decirse, "por la tangente".

Se trata de determinar el lugar que ocupan modo y voz, focalización y narración, en el modelo de "producción" narrativa. Ricoeur (1984: 148) encuentra una única diferencia entre ambas categorías:

El punto de vista se relaciona todavía con un problema de composición (como se ha visto con Uspensky), por tanto permanece todavía en el campo de investigación de la configuración narrativa; la voz, en cambio, implica ya problemas de comunicación [...]; se sitúa así en el punto de transición entre configuración y refiguración.

Una localización equivalente plantea Segre (1981: 98) en el esquema:

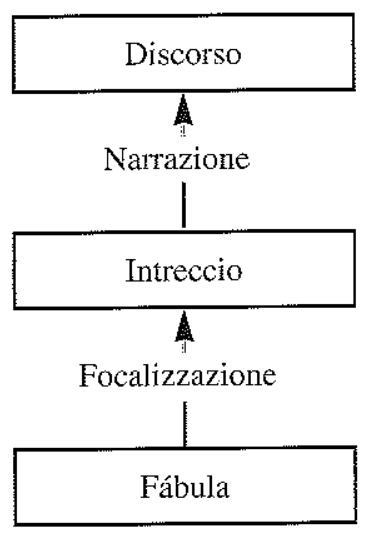




\section{PROBLEMAS TEÓRICOS DE LA FOCALIZACIÓN NARRATIVA}

De acuerdo con él, la cuestión de la "prioridad" dependería precisamente del punto de vista que se adopte: de la estructura profunda a la superficial o viceversa.

Abandonemos, llegados a este punto, el relato literario para examinar la relación entre narrador y focalizador en el terreno paradójico de las "narraciones sin narrador" (Nelles, 1990: 373). Me refiero, en particular, al cine. El caso del teatro es todavía más grave, pues si en aquél nadie "habla" pero alguien "ve", en éste, que carece en absoluto de instancia "vocal", plantea serios problemas incluso la admisión de una instancia "perceptiva".

Robert Burgoyne (1991) defiende, frente a las teorías del "no-narrador", la incorporación al cine del concepto de "narrador", en el marco de la teoría de la narración "impersonal" de Ryan y Doležel. Sus argumentos me parecen tan consistentes como las razones de los que se niegan a identificar esa "instancia" (útil sin duda para dar cuenta de la "composición" cinematográfica) con el narrador (literario). Tras asistir al trasvase, necesariamente metafórico (inadecuado, por tanto, en alguna medida) y problemático de hecho, a la narración verbal del concepto de "punto de vista", literalmente apropiado a las representaciones espectaculares y, en general, visuales, ¿será verdaderamente necesario consumar el préstamo inverso: trasladar, metafóricamente por fuerza, el concepto "vocal" de narrador allí donde nadie "cuenta" (con la voz)? En algún otro lugar (García-Barrientos, 1985) he manifestado mi escándalo ante nociones como la de "dramaturgia en primera persona". Y recordando el reproche de Genette a las teorías del punto de vista, ¿cómo llamar narrador a alguien (o a algo) que, por definición, "no abre la boca"? Creo que el modelo de la focalización o, más ampliamente, del punto de vista resulta más apropiado para definir la "instancia" visual (equivalente, aunque no idéntica y no siempre, al narrador de los relatos literarios) en el cine y que el concepto de focalizador, con las precisiones apuntadas (entre ellas, la distinción "personal / impersonal"), puede dar cuenta con ventaja (desde luego, en cuanto a propiedad) de todas las cuestiones que plantea Burgoyne, particularmente las de la "autoridad" y la "distancia" (valoraciones, comentarios, ironía) de la instancia "discursiva". En cuanto al teatro, lo que he definido en Drama y tiempo como "dramaturgo" (1991: 116-121) podría hacerse corresponder quizás con una "figura" como lá del focalizador, pero de ninguna manera con la del narrador.

\section{Planos de focalización}

Resolvamos, pues, provisionalmente, la competencia entre "focalizador" y narrador concediendo la primacía al segundo en el relato verbal y al primero en el espectacular. $\mathrm{Pa}$ rece claro que un narrador verbal será una instancia "secundaria" en el cine (caso de una voz "off") y "falsa" en el teatro, en el que los así llamados no pueden ser otra cosa que verdaderos personajes "pseudonarradores". Sobre esta hipótesis convendrá examinar la posibilidad de trasvasar al "focalizador" funciones o poderes que en literatura narrativa se atribuyen al narrador o plantean un problema de competencias entre ambos. Ello implica volver sobre el concepto "confuso" de punto de vista.

Después de haber insistido en relacionar focalización y "composición", parece aconsejable recordar los distintos planos en que sitúa Uspensky (1970) los problemas relativos al punto de vista, como centro de una "poética de la composición":

$\left.1 .^{\circ}\right)$ Plano de la apreciación o grado de coincidencia ideológica entre narrador y personaje (para cuyo estudio resulta decisiva la contribución de Bajtin); 


\section{JOSÉ LUIS GARCÍA BARRIENTOS}

$2^{\circ} .^{\circ}$ Plano verbal o fraseológico, que se refiere a la relación entre discursos del narrador y del personaje (lo que corresponde, en el modelo de Genette, a la "distancia" en el "relato de palabras"); naje; $y$

3. ) Plano espacio-temporal: distancias espaciales y temporales entre narrador y perso-

4..$\left.^{\circ}\right)$ Plano psicológico, al que se suelen reducir los problemas del punto de vista y en el que distingue cuatro posibilidades principales (que corresponderían, en términos de Genette, a las focalizaciones externa, interna fija, interna variable y cero u omnisciencia).

En todos los niveles considera fundamental la dicotomía entre punto de vista externo e interno (apud. Todorov, 1972: 111-12).

De forma similar, Chatman (1978: 151-152) distingue tres funciones en el punto de vista, que suelen confundirse: la perceptiva, la conceptual y la del punto de interés, que más tarde (1986) dan lugar a las categorías de "filtro" (filter), "ángulo" (slant), "foco de interés" (interest-focus) y "centro" (center).

Rimmon-Kenan (1983) propone una síntesis entre los planos de Uspensky y la dicotomía (externa/interna) de Bal según el foco esté situado fuera o dentro de los sucesos focalizados, de la que resulta:

\begin{tabular}{l|l} 
Plano perceptivo & $\begin{array}{l}\text { Espacial (Externa/Interna) } \\
\text { Temporal (Externa/Interna) }\end{array}$ \\
Plano psicológico & $\begin{array}{l}\text { Componente cognitivo (Externa/Interna) } \\
\text { Componente emotivo (Externa/Interna) }\end{array}$
\end{tabular}

La distinción entre plano perceptivo y psicológico recuerda la de Bal entre objetos perceptibles e imperceptibles, que ya descartamos antes. El plano fraseológico de Uspensky, independientemente de que pueda tratarse, más que de otro, del plano en el que convergen los demás, como sostiene Pozuelo Yvancos (1984: 251-257), en cuanto exclusivo del relato literario (aunque fundamental en él), queda fuera de nuestro interés. EI "ángulo conceptual" (slant) de Chatman puede emparentarse con la "apreciación" ideológica de Uspensky, pero no, me parece, con el componente cognitivo (ni emotivo) de Rimmon-Kenan. Parece útil, por último, considerar separadamente el plano espacial y el temporal.

Se trata ahora de examinar qué distinciones resultarán pertinentes para una teoría "general" de la focalización. Todas ellas pueden definirse en términos de relación entre punto focalizante y objeto focalizado. Y dicha relación se puede establecer, para cada plano, como oposición discreta (externa/interna), y también, lo que quizás resulte más productivo para el análisis, como grado de distancia (o identificación) entre focalizador y focalizado (para el objeto sigue en pie la distinción "interior"/"exterior"). Resultarían así cinco niveles de análisis:

$\left.1 .^{\circ}\right)$ Focalización espacial: con oposición discreta entre externa o visión panorámica (de ojo de pájaro) e interna o visión desde un punto de mira (observador) limitado. En términos de "distancia", se puede establecer una distribución más matizada, como la que define en el cine los distintos "planos": general, largo, medio, corto, "primer" y primerísimo (y que pueden todos corresponder to mismo a un focalizador impersonal que personal).

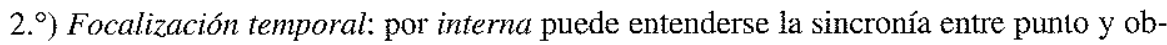
jeto, focalizador y focalizado: distancia cero o identificación temporal. Por externa habría que entender las perspectivas retrospectiva y prospectiva (para el focalizador personal) y la 


\section{PROBLEMAS TEÓRICOS DE LA FOCALIZACIÓN NARRATIVA}

que llama Rimmon-Kenan "pancrónica" (para el impersonal). Si en ésta última la distancia podría considerarse infinita, en las otras dos será pertinente determinar su magnitud.

Este tipo, que podría parecer a primera vista poco relevante, resulta en determinados casos fundamental. Pienso, por ejemplo, en los relatos en que un mismo personaje es narrador y héroe, focalizador y focalizado. Ifri (1987) ha propuesto una distinción entre autobiografía y novela autobiográfica recurriendo a la focalización, en cuya base (aunque no expresamente) se encuentra la distancia temporal (retrospectiva) entre focalizador (narrador) y focalizado (héroe): máxima en la autobiografía y mínima en la novela autobiográfica.

$\left.3 .^{\circ}\right)$ Focalización cognoscitiva: a la que en realidad se reduce la consideración "simple" de la focalización. Se refiere al conocimiento que el focalizador filtra de lo focalizado. La insuficiencia de la oposición discreta entre conocimiento restringido (interna) y no restringido (externa), reclama el criterio complementario de los grados de distancia entre sujeto (punto) y objeto de conocimiento. Es el plano en el que se sitúa la tipología de Genette.

$\left.4 .^{\circ}\right)$ Focalización afectiva. Paralela a la anterior, pero en el orden del sentir, no del saber. Abarca los distintos grados de implicación emotiva que van de la total identificación (interna) a la completa distancia (externa).

Para todos los tipos conviene recordar la distinción, propuesta antes, entre focalización explícita e implícita.

$5^{\circ}{ }^{\circ}$ Focalización ideológica (entendiendo ampliamente ideología como "visión del mundo", sistema de valores, concepción de la vida, etc., lo que implica puntos de vista moral, filosófico, político, cultural, religioso, etc.): este quinto tipo es de un orden distinto a los anteriores y de una complejidad mayor. Implica valoraciones o comentarios (no necesariamente verbales) que podrían hacer pensar en remitirlo a una categoría como la del "autor implícito" (Booth). En términos visuales, se pođría asociar al "ángulo" cinematográfico. Y es el plano que autoriza a hablar de un focalizador "irónico". No se confunde con las focalizaciones cognoscitiva y afectiva. $\mathrm{Ni}$ el conocimiento, mayor o menor, del objeto ni el grado de simpatía con que se percibe o se presenta determinan necesariamente la identificación o la distancia ideológica del focalizador respecto a él.

El mayor interés de este tipo de focalización reside en que remite a otras cuestiones de enorme interés para esta "ampliación" del concepto. En particular, la de la distinción de Booth (1961b) entre narrador "fiable" y "no-fiable", que entra en directa relación con la teoría de la narración impersonal y personal (cfr. Doležel, 1980, y Ryan, 1981). Ya sugerimos antes la conveniencia de que tal đistinción (y sus implicaciones) se transfiera, al pasar de la narración literaria a la espectacular, del narrador al focalizador. Lo mismo que Growinski (1967) afirma del narrador en primera persona se puede decir del focalizador personal (por ejemplo, en el cine): condena al espectador a la incertidumbre, lo focalizado por él no es susceptible de verificación, puede informar o desinformar, el hecho de que disponga de una información es tan importante como el hecho de que carezca de ella; plantea, en definitiva, una lucha por la autenticidad. Y parafraseando a Ryan (1985: 751) se puede decir que las informaciones (por ejemplo, las imágenes) filtradas por un focalizador impersonal "pueden ser automáticamente vistas como constitutivas del mundo que ellas representan", mientras que las filtradas por un focalizador personal "pueden o no estar libres de error".

Ruth Ronen (1990: 306) va más allá y defiende esta cesión de poderes (del narrađor al focalizador) también para la narración verbal. En sus palabras: "Un grado superior de autoridad decide, detrás del locutor, el grado de autenticidad o de 'factualidad' de las proposiciones que emanan de ese locutor". Y ese grado corresponde al focalizador, que se convierte en 


\section{JOSÉ LUIS GARCÍA BARRIENTOS}

la instancia primordial de los "mundos ficcionales" en general, cuya estructura modal "está producida por la interacción entre focalizadores y objetos".

\section{Focalización y receptor}

Dos palabras tan sólo para no terminar sin aludir siquiera a un factor que me parece destinado a desempeñar una función determinante en una teoría general de la focalización y al que, sin embargo, no suele prestársele demasiada atención. Me refiero al receptor: lector o espectador.

Se recordará que Ricoeur situaba el punto de vista en el plano de la "configuración" y la voz en el de la comunicación. Sin embargo, a renglón seguido añadía que "son precisamente estas dos funciones las que son intercambiables. Todo punto de vista es la invitación al lector para que dirija su mirada en el mismo sentido que el autor o el personaje" (1984: 148-149). Un papel aún más activo atribuye Lintvelt al lector cuando afirma que la perspectiva depende del "centro de orientación del lector, y por consiguiente el tipo narrativo está determinado por la posición imaginaria que el lector ocupa en el texto narrativo" (1981:39).

La cuestión es, me parece, de la máxima importancia. No otro que el lector es quien "ve" o "percibe" efectivamente la "información narrativa". Puede desempeñar por ello un papel (digamos) de "control" sobre la categoría que estudiamos. Tomándolo como punto de referencia se puede poner coto a Ia tendencia (abusiva) a multiplicar las "instancias" de focalización y a llevar el análisis hasta niveles verdaderamente microscópicos. Pienso, por ejemplo, en la consideración de que cada parlamento de un personaje implica un cambio de focalización y, a su vez, cada cambio de focalización un cambio de nivel narrativo, con lo que el concepto mismo de "engaste" o incrustación acaba por disolverse. La función de control del lector o el espectador se puede formular, como una regla, así: "Cualquier tipo o cambio de focalización exige la identificación perceptiva de receptor y focalizador" (lo que no ocurre, a mi juicio, cada vez que un personaje toma la palabra, sino, en todo caso, cuando la toma para contar "otra" historia).

En el cine, algunos aspectos presentan quizás una mayor complejidad, pero otros, como los señalados antes, aparecen más claros. La focalización visual u "ocularización", es decir, el punto de vista stricto sensu, sufrirá, en general, más variaciones y con más frecuencia en el cine que en la literatura. En rigor, cada plano fijo y cada desplazamiento de la cámara dentro de un mismo plano implica un cambio de focalización visual, precisamente porque el ojo del espectador se identifica, por definición, con el del aparato tomavistas. Sin embargo, parece evidente que los discursos de los personajes no imponen en absoluto cambios de focalización ni de nivel diegético en el cine. Ni siquiera cuando el personaje "cuenta" una historia, cuando su discurso es propiamente narrativo. Para que se produzca un cambio de nivel (y de focalización) es preciso que la cámara penetre en el universo (metadiegético) de esa historia "segunda", que la "ponga en imágenes", sustituyendo, y eliminando por tanto, so pena de incurrir en redundancia (tanto menos tolerable cuanto más completa pretenda ser), la narración verbal del personaje, que no sólo desaparece (de la imagen) como narrador, sino que también enmudece, total o parcialmente. Piénsese, por ejemplo en la versión cinematográfica, que dirigió W. Haas, de El manuscrito encontrado en Zaragoza, de Jan Potocki.

La relación entre focalización y receptor adquiere perfiles especialmente nítidos en el teatro, en que la representación se efectúa sin mediación vocal ni ocular alguna, donde el espectador ve el mundo representado "por sus propios ojos" y por fuerza "desde fuera". Puede así entenderse, al menos en lo que a la percepción sensorial se refiere, como el ejemplo para- 


\section{PROBLEMAS TEÓRICOS DE LA FOCALIZACIÓN NARRATIVA}

digmático de la focalización externa. Sin embargo, nos parece que haya que descartar ciertas formas de focalización teatral interna (antes preguntábamos: ¿Tendrá que ser necesariamente "interior"?). El teatro de Buero Vallejo es un buen ejemplo de persistente tentativa en esta dirección (cfr. García-Barrientos, 1985).

Como afirma Travieso Ganaza (1990: 134), "la focalización en el teatro será función del grado en que el espectador se asocie al punto de vista de un personaje". En términos prácticos, el espectador se convierte en el factor determinante de la implantación o no de la focalización interna en el teatro, del éxito o fracaso de "experimentos" de participación como los que propone Buero en tantas obras. Lo que la crítica ha llamado "efectos de inmersión" (verdaderos ensayos de focalización interna) cumplen su objetivo sólo si el público "entra en el juego" y se identifica con la visión subjetiva del personaje. En caso contrario (como ocurrió con el "oscuro" de En la ardiente oscuridad, que pretendía la identificación. con la "visión" de los personajes, ciegos, que ocupaban la escena y que el público del estreno entendió como un apagón del teatro), el intento frustrado de imponer un punto de vista interior se traduce en la quiebra del "pacto narrativo" o representativo: el público "sale del juego" y se distancia absolutamente del universo de ficción.

Desde el punto de vista teórico, la función de control del espectador está en la base de mi definición del "dramaturgo" (1991: 116-121) como contrafigura del público, como un sujeto hipotético que hubiera "visto" el drama antes que el espectador, pero desde el sitio o a través de los ojos de éste.

\section{Referencias bibliográficas}

ALPHEN, Ernst Van (1990), "The narrative of perception and the perception of narrative", Poetics Today, 11:3, págs. 483-509.

BAJTIN, Mijail (1963), La poétique de Dostö̈evski, París, Seuil, 1970.

- (1978), Esthétique et théorie du roman, París, Gallimard.

BAL, Mieke (1977), "Narration et focalisation. Pour une théorie des instances du récit", Poétique, 29, págs. 107-127.

— (1977b), Narratologie (Essais pour la signification narrative dans quatre romans modernes), París, Klincksieck.

— (1981), "Notes on narrative embedding", Poetics Today, 2:2, págs. 41-59.

— (1981b), "The laughing mice or: on focalization", Poetics Today, 2:2, págs. 202-210.

- (1983), "The narrating and the focalizing: A theory of agents in narrative", Style, 17:2, págs. 234-269.

- (1985), Teoría de la narrativa. Una introducción a la narratología, Madrid, Cátedra.

BANFIELD, Ann (1981), "Reflective and non-reflective consciousness in the language of fiction", Poetics Today, 2:2, págs. 61-76.

- (1982), Unspeakable sentences: narration and representation in the language of fiction, Londres y Nueva York, Routledge and Kegan Paul.

BARTHES, Roland (1966), "Introduction à 1'analyse structurale des récits", en Poétique du récit, París, Seuil, 1977, págs. $7-57$.

BERENDSEN, Marjet (1984), "The Teller and the Observer: Narration and focalization in narrative texts”, Style, 18, págs. 140-158.

BLIN, Georges (1954), Stendhal et les problémes du roman, París, Corti. 


\section{JOSÉ LUIS GARCÍA BARRIENTOS}

BOOTH, Wayne C. (1961), La retórica de la ficción, Barcelona, Bosch, 1974.

- (1961b), "Distance et point de vue. Essai de classification", en Poétique du récit, París, Seuil, 1977, págs. 85-113.

BRINTON, Laurel (1980), “'Representated perception': A study in narrative style”, Poetics, IX, 4, págs. 363-381.

BRIOSI, Sandro (1986), "La narratologie et la question de 1'auteur", Poétique, 68, págs. 507-519.

BROOKS, Cleanth y Robert P. WARREN (1943), Understanding fiction, Nueva York, Rinehart y Winston, 1967.

BRONZWAER, W. (1981), "Mieke Bal's concept of focalization: A critical note", Poetics Today, 2:2, págs. 193-201.

BURGOYNE, Robert (1991), "Le narrateur au cinema. Logique et pragmatique de la narration impersonelle”, Poétique, 87, págs. 289-311.

CHATMAN, Seymour (1978), Story and discourse. Narrative structure in fiction and film, Ithaca, Londres, Cornell University Press.

- (1986), "Characters and narrators: filter, center, slant and interest-focus", Poetics Today, 7:2, págs. 189-204.

COHN, Dorrit (1978), La transparence intérieur: Modes de representation de la vie psychique dans le roman, París, Seuil, 1981.

— (1985), "K fait son entrée au château", Poétique, 61, págs. 111-127.

- (1990), "Signpost of fictionality: A narratological perspective", Poetics Today, 11:4, págs. 775-804.

COHN, Dorrit y Gérard GENETTE (1985), "Nouveaux discours du récit", Poétique, 61, págs. 101-109.

CORDESSE, Gérard (1988), "Narration et focalisation", Poétique, 76, págs. 487-498.

DOLEŽEL, Lubomír (1967), "The typology of the narrator: Point of view in fiction", en To Honor R. Jakobson, La Haya-París, Mouton, t. I, págs. 541-552.

- (1973), Narrative models in czech literature, Toronto, U.T.P.

- (1980), "Truth and authenticity in narrative", Poetics Today, 1:3, págs. 7-25.

EDMISTON, William F. (1989), "Focalization and the first-person narrator: a revision of the theory”, Poetics Today, 10:4, págs. 729-744.

FRIEDMAN, Norman (1965), "Point of view in fiction: the development of a critical concept", P.M.L.A., LXX, págs. 1.160-1.184.

GARCÍA-BARRIENTOS, José-Luis (1985), "Punto de vista y teatralidad (El ejemplo de Buero Vallejo)", en M. Á. Garrido Gallardo (ed.), Teoría semiótica. Lenguajes y textos hispánicos, Madrid, CSIC, págs. 627-635.

- (1991), Drama y tiempo. Dramatología I, Madrid, CSIC.

GENETTE, Gérard (1972), "Discours du récit. Essai de méthode", en Figures III, París, Seuil, págs. 62-282.

- (1983), Nouveau discours du récit, París, Seuil.

— (1990), "Fictional narrative, factual narrative", Poetics Today, 11:4, págs. 755-774.

GLOWINSKI, Michał (1967), "Sur le roman à la première personne", Poétique, 72, 1987, págs. 497-507. 


\section{PROBLEMAS TEÓRICOS DE LA FOCALIZACIÓN NARRATIVA}

GUTIÉRREZ, Raquel (1986), "La focalización: Génesis y desarrollo de un concepto", Semiosis, 17, págs. 113-135.

HAMBURGER, Käte (1957), Logique des genres littéraires, París, Seuil, 1986.

HUSSON, Didier (1991), "Logique des possibles narratifs. Étude des compatibilités entre les variables du récit", Poétique, 87, págs. 289-311.

IFRI, Pascal A. (1987), "Focalisations et récits autobiographiques. L'exemple de Gide", Poétique, 72, págs. 483-495.

JAMES, Henry (1975), El futuro de la novela, Madrid, Taurus.

JOST, François (1983), "Narration(s): en deçà et au delà", Communications, 38, págs. 192209.

- (1984), "Le regard romanesque. Ocularisation et focalisation", Hors cadre, 2, págs. 67-86.

LINTVELT, Jaap (1978), "Modèle discoursive du récit encadré. Rhétorique et idéologie dans les Illustres Françaises de Robert Challe", Poétique, 35, págs. 352-366.

— (1981), Essai de typologie narrative. Le "point de vue". Théorie et analyse, París, Corti.

LOTMAN, Yuri (1970), Estructura del texto artístico. Madrid, Istmo.

LUBBOCK, Percy (1921), The craft of fiction, Londres, Jonathan Cape.

MATHIEU, Michel (1977), "Analyse du récit (1). La structure des histoires" y "Analyse du récit (2). Le discours narrative”, Poétique, 30, págs. 226-259.

MATHIEU-COLAS, Michel (1986), "Frontières de la narratologie", Poétique, 65, págs. 91110.

NELLES, William (1990), "Getting focalization into focus", Poetics Today, 11:2, págs. 365382.

POUILLON, Jean (1946), Temps et roman, París, Gallimard.

POZUELO YVANCOS, José María (1984), "Focalización y estructura textual. La capilla de Brandeso en la Sonata de Otoño", Estudios de lingüística (Universidad de Alicante), 2, págs. 251-271.

REES, Cees J. Van (1985), "Implicit premises on text and reader in Genette's study of narrative mood", Poetics, XIV, 5, págs. 445-464.

REISZ DE RIVAROLA, Susana (1985), "Voces y conciencias modelizantes en el relato literario-ficcional”, en M. Á. Garrido Gallardo (ed.), Teoría semiótica. Lenguajes y textos hispánicos, Madrid, CSIC, págs. 561-584.

RICOEUR, Paul (1983), Temps et récit I, París, Seuil.

- (1984), Temps et récit II. La configuration dans le récit de fiction, París, Seuil.

RIMMON-KENAN, Shlomith (1976), "A comprehensive theory of narrative: Genette's Figures III and the structuralist study of fiction", PTL, 1:1, págs. 33-36.

- (1983), Narrative fiction: contemporary poetics, Londres y Nueva York, Methuen.

ROBBE-GRILLET, Alain (1958), "Note sur la localisation et les déplacements du point de vue dans la description romanesque", Revue des Lettres Modernes, 36-38, págs. 128-130.

ROMBERG, Bertil (1962), Studies in the narrative technique of the first person novel, Estocolmo, Lund, Almqvist y Wiksell. 


\section{JOSÉ LUIS GARCÍA BARRIENTOS}

RONEN, Ruth (1990), "La focalisation dans les mondes fictionnels", Poétique, 83, págs. 305-322.

ROSSUM-GUYON, Françoise Van (1970), "Point de vue ou perspective narrative. Théorie et concepts critiques", Poétique, 4, págs. 476-497.

RUBIO MONTANER, Pilar (1990), "Primacía de la focalización en la instancia narrativa", Revista de Literatura, LI, 103, págs. 47-66.

RYAN, Marie-Laure (1981), "The pragmatics of personal and impersonal fiction", Poetics, X, 6, págs. 517-539.

- (1985), "The modal structure of narrative universes", Poetics Today, 6:4, págs. 717-755.

SÁNCHEZ-REY, Alfonso (1991), El lenguaje literario de la "nueva novela" hispánica, Madrid, Mapfre-América.

SEGRE, Cesare (1981), "Punto di vista e polifonia nell'analisi narratologica", en Teatro $e$ romanzo. Due tipi di comunicazione letteraria, Turin, Einaudi, págs. 85-101.

SOURIAU, Étienne (1950), Les deux cent mille situations dramatiques, París, Flammarion.

STANZEL, Frank K. (1955), Die typischen Erzählsituationem in Roman, dargestellt an "Tom Jones", "Moby Dick", "The Ambassadors", "Ulisses", Sttutgart, W. Branmüller.

— (1979), Theorie des Erzählens, Göttingen, Van der Hoeck y Ruprecht, 1982 (2. a ed. rev.).

- (1990), "A low-structuralist at bay? Further thoughts on A theory of narrative", Poetics Today, 11:4, págs. 805-816.

TACCA, Óscar (1973), Las voces de la novela, Madrid, Gredos, (B.R.H.), 1978 (2. ed. corregida y aumentada).

TODOROV, Tzvetan (1966), "Les catégories du récit littéraire", Communications, 8, págs. 125-151.

— (1972), "La poétique en U.R.S.S.", Poétique, 9, págs. 102-115.

- (1972b), "Visión en la narrativa", en DUCROT, O., y T. TODOROV, Diccionario enciclopédico de las ciencias del lenguaje, Buenos Aires, Siglo XXI, 1974, págs. 369- 374.

- (1973), Poétique, París, Seuil.

TRAVIESO GANAZA, Mercedes (1990), "La distance théâtrale dans 1e Jeu de Saint Nicolas de Jean Bodel", Estudios de lengua y literatura francesas (Universidad de Cadiz), 4, págs. 131-138.

USPENSKY, Boris (1970), A poetics of composition. The structure of artistic text and typology of a compositional form, Berkeley, Los Ángeles, University of California Press, 1973.

VILLANUEVA, Darío (1991), "Historia, realidad y ficción en el discurso narrativo", en El polen de ideas, Barcelona, PPU, págs. 115-130.

VITOUX, Pierre (1975), "Le récit dans The Ambassadors", Poétique, 34, págs. 460-478.

— (1982), "Le jeu de la focalisation", Poétique, 51, págs. 359-368. 